\title{
OPTIMIZATION OF THE DESIGN OF RADIAL FLOW PUMP IMPELLER THOUGH CFD ANALYSIS
}

\author{
Krishna Kumar Yadav', Karun Mendiratta ${ }^{2}$, V K Gahlot ${ }^{3}$ \\ ${ }^{I}$ Assistant Professor, Department of Mechanical Engineering, NIET, Greater Noida, UP, India \\ ${ }^{2}$ Assistant Professor, Department of Mechanical Engineering, NIET, Greater Noida, UP, India \\ ${ }^{3}$ Professor, Department of Civil Engineering, MANIT, Bhopal, MP, India
}

\begin{abstract}
It is very difficult and complex to analyze the hydraulic performance and characteristics of a centrifugal pump. Additionally, pump operation hugely depends on a large number of interdependent variables. This work aims to study the performance analysis of a centrifugal radial flow pump designed to deliver $0.0074 \mathrm{~m}^{3} / \mathrm{s}$ of water with a head of $30 \mathrm{~m}$ at a speed of $2870 \mathrm{rpm}$ using ANSYS CFX (ver.14.0). The pump unit has been modeled using PTC Creo (ver. 2.0). In order to analyze the flow, Computation fluid dynamics (CFD) has been used. The performance of the pump was first determined using the existing number of the blades and then, the number of blades has been varied to analyze the pump's performance. The results show that for the optimized value, pump efficiency increased by $2.23 \%$.
\end{abstract}

Keywords: Computational Fluid Dynamics (CFD) Analysis, Radial Flow Pump, Overall Efficiency.

\section{INTRODUCTION}

Energy is added continuously in rotor-dynamic or dynamic pressure pumps, in order to increase the fluid velocity within the machine. The centrifugal pumps have snail-shaped casing which can easily be identified and have application all around in our homes and industries as well. Radial flow centrifugal pumps are widely used where moderate head and discharge are required. The liquid enters through impeller axially at the centre (eye) and acquires tangential and radial velocity as a result of the momentum transfer. The flow exits the impeller radially outwards into the volute, post gaining speed as well as pressure. Based on impeller blade geometry, centrifugal pumps can be classified as; 1) Backward inclined blades, 2) Radial or Straight blades, and 3) Forward inclined blades. The most common type is Backward inclined blade which yields highest efficiency out of these three due to least amount of turning of fluid. Radial blade types (straight blades) are known to have simplest geometry and produce greatest pressure rise for a wide range of volume flow rates. Forward inclined blades generally have more number of blades that are smaller and produces constant pressure rise (although lower than that of backward inclined or radial blades).

These days due to ever increasing demand of improved performance, pump designers are being challenged to provide the machines which are more efficiently, quiet, and reliable with lower cost. As discussed by Gahlot \& Nyiri [1], it is imperative to define the shape and size of vanes. It was observed that with short passage length, the angle of divergence might increase which in turn results in flow separation and eddy formation. However, longer passage length contributes to higher frictional losses. So, an efficient blade profile requires an appropriate blade design method.
Jain et al. [2] investigated the methods to optimize the geometric and operational parameters of a centrifugal pump running in turbine mode. The rotational speed was varied 900 to $1500 \mathrm{rpm}$ with no, $10 \%$ trimming, and $20 \%$ trimming of impellers. The results revealed that the performance increases at lower speeds rather than rated speed. Blade rounding led to $3-4 \%$ rise in efficiency at rated speed with the original impeller. Oyelami et al. [3] evaluated the performance of a designed blower with different impeller/vane profiles. It was observed that the amount of energy imparted to the fluid is proportional to velocity at the edge or tip of the vane of impeller. Moreover, the performance was influenced by the fact that the impeller is open or close. Closed impeller having backward curved vanes had the best performance or efficiency with respect to output speed and flow rate.

A numerical model, simulation, and analysis for 3-D turbulent flow in centrifugal pump impellers have been performed by several researchers. Solved by RANS equations, it was observed that the hydraulic efficiency can be increased by optimizing the impeller geometry with typical errors ranging below $10 \%$ when compared to experimental data $[4,5]$. Conformal mapping and boundary element technique was used by Jude \& Homentcovschi [6], to study the flow through 2-D centrifugal impeller with equiangular blades of an arbitrary geometry. The result claimed a good agreement with previous theoretical results for logarithmic spiral blades with only minute difference. Efforts have been made to study the response characteristics of pump-turbine impellers. It was observed by Egusquiza et al. [7], that the deformation in impeller occurs in axial direction, and the eye in radial direction. With increase in frequency, deformation in band decreased and the crown and band deformed in counter-phase. But towards the end, band deformation was more significant than the crown. 
PIV and CFD tools, such as meshing technique have provided a prudent solution which can assist in easy analysis of physical nature of flow. Karanth \& Sharma [8], predicted the flow's behavior due to the radial gap using numerical methodology and moving mesh technique. Presence of optimum radial gap provides lower loss coefficient, better energy conversion by impeller, and improved energy transformation by diffuser. Effect of trimming of impeller diameter in a radial-submersible pump was studied by Pandit et al. [9]. The capacity of the original impeller changed with an approximate $10 \%$ reduction. The method was found useful correction technique for oversized impellers, which can eliminate the need to build a new one.

It has been observed by Somashekar \& Purushothama [10], that the Design, operation and refurbishment of centrifugal pumps have strong relation with cavitation phenomena [10]. The flow simulation was carried out on a radial flow pump in the rotation frame of reference with standard (k- $\varepsilon$ ) turbulence model. Cavitation inception took place near suction surface, and the cavitation zone expands towards the trailing edge.

CFD is being used as an effective tool by many researchers to carry out different studies and investigations on the centrifugal pumps. CFD analysis can prove to be a worthy tool when compared to trial and error methods [11]. Various blade design methods are being used to analyze and compare the efficiency and head of radial flow pumps at various discharge conditions. Steady-state 3-D Navier-Stokes equations coupled with the k-epsilon turbulence model have also been used [12]. Ajith \& Isaac [13], investigated the flow in the centrifugal pump impeller having both forward and backward curved vanes using the ANSYS. The backward curved vanes have better performance than its counterpart. CFD has also been used to study, analyze and predict the factors affecting impeller performance of a radial flow-type impeller of a centrifugal pump. Some studies like of Kaewnai et al. [14], have revealed that the surface roughness value have high impact on the losses, i.e. with increase in surface roughness, the loss coefficient also increased. It has been observed that, the pump performance is greatly affected by blade width (b), with increase of $b$, efficiency and head of the pump under various working conditions decreases. As $b$ grows, the leakage increases, but decreases as the discharge grows [15].

As there are very few papers that explain the radial type vane profile design procedure, designers are forced to reverse engineer the vane profiles popularly available in the market. This paper is an effort to give a step by step guidance to design a radial type vane profile by Double Arc method. This research aims to analyze the effect of number of blades on the performance of radial flow pump, and also to find the optimal value in order to enhance the overall efficiency of the pump.

\section{PUMP SPECIFICATIONS}

\subsection{Impeller Geometry}

The performance of a radial flow pump is hugely affected by its impeller geometry. In the present work, a pump has been designed with its specifications as shown in Table-1., and effect of number of blades on its performance has been analyzed. Detailed study of the impeller geometric features has also been done. The designed model of pump and impeller is shown in Fig.1 and Fig.2.

Table-1: Design specification of pump

\begin{tabular}{|c|c|}
\hline Design & Specifications \\
\hline Flow rate $\left(\mathrm{m}^{3} / \mathrm{s}\right)$ & 0.0074 \\
\hline Head $(\mathrm{m})$ & 30 \\
\hline Rotating speed $(\mathrm{rpm})$ & 2870 \\
\hline
\end{tabular}

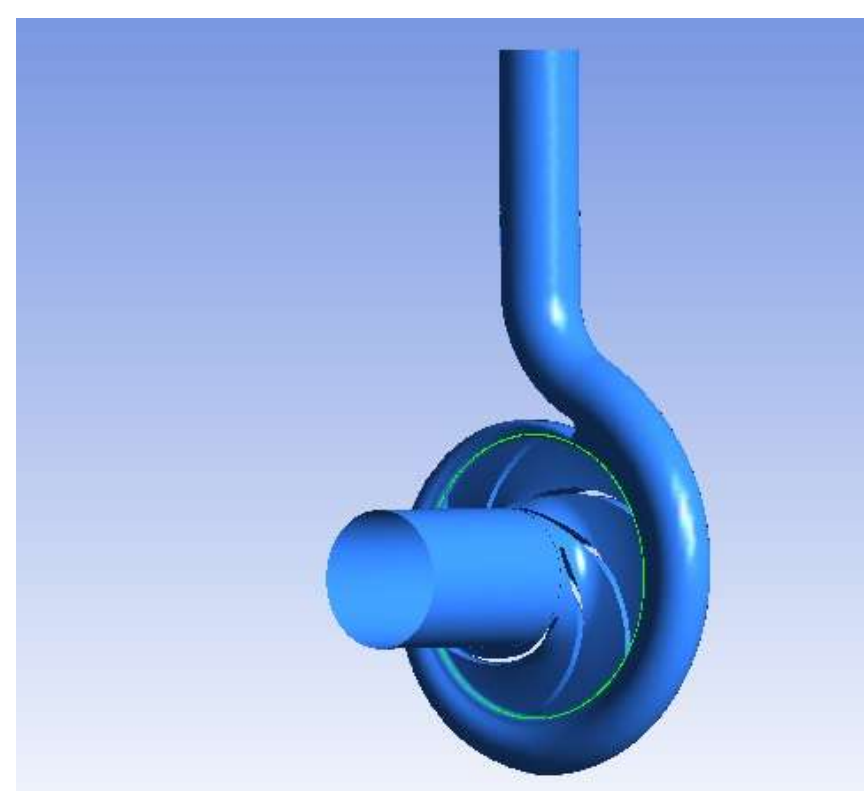

Fig-1: Model of Pump

To investigate single or combined effects of these features on the flow and impeller performance, parameterization has also performed by reducing the number of controlling geometric variables. The values are shown in Table-2.

Table-2: Geometrical features of the impeller

\begin{tabular}{|c|c|}
\hline Parameter & Size \\
\hline Inlet diameter $\left(\mathrm{d}_{1}\right)$ & $66 \mathrm{~mm}$ \\
\hline Outlet diameter $\left(\mathrm{d}_{2}\right)$ & $172 \mathrm{~mm}$ \\
\hline Vane inlet angle $\left(\beta_{1}\right)$ & $23^{\circ}$ \\
\hline Vane outlet angle $\left(\beta_{2}\right)$ & $29^{\circ}$ \\
\hline Number of blades $(\mathrm{z})$ & 6 \\
\hline Blade thickness $(\mathrm{t})$ & $10 \mathrm{~mm}$ \\
\hline Shaft diameter $\left(\mathrm{d}_{\mathrm{sh}}\right)$ & $25 \mathrm{~mm}$ \\
\hline Blade inlet height $(\mathrm{b} 1)$ & $15 \mathrm{~mm}$ \\
\hline Blade outlet height $(\mathrm{b} 2)$ & $6 \mathrm{~mm}$ \\
\hline
\end{tabular}




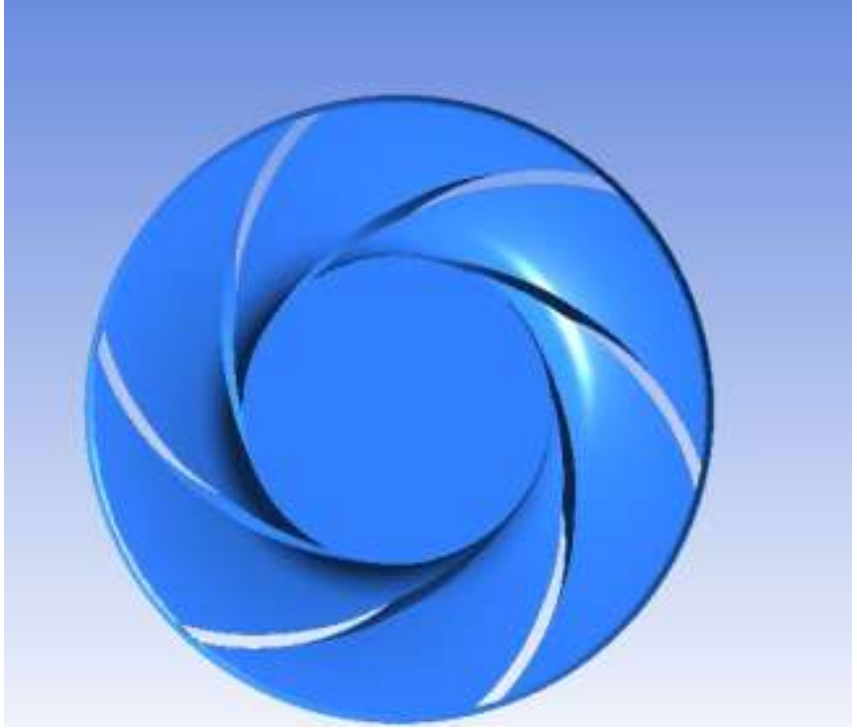

Fig-2: Model of Pump Impeller

\section{METHOD FOR CONSTRUCTING THE VANE}

SHAPE

\subsection{Circular Arc Method}

The impeller is divided into number of concentric rings between radius $R_{1}$ and $R_{2}$ in a random manner. $A$ vane thus can be defined by using one or two arcs of a circle. Out of Single arc method and two arcs method, the latter gives better results.

Vane shape in two arc method is constructed by joining arcs of two circles which are drawn through points $\mathrm{A}$ and $\mathrm{B}$. The circle passing through inlet edge of the blades of diameter is divided into ' $\mathrm{z}$ ' equal parts. Tangents: $\mathrm{C}_{1} \mathrm{P}_{1}, \mathrm{C}_{2} \mathrm{P}_{2}$ are drawn from the division points $\mathrm{C}_{1}, \mathrm{C}_{2}, \mathrm{C}_{3}$, etc which touch the circle of radius $\delta=d_{1} \operatorname{Sin} \beta_{1}$. From these points of intersection $\left(P_{1}\right.$, $\mathrm{P}_{2}$ etc.), arcs of radius $\rho_{1}=\mathrm{P}_{1} \mathrm{C}_{1}=\mathrm{P}_{2} \mathrm{C}_{2}$ and so on, are drawn. Each of the arc forms the inlet part of the vane, as well as an approximate portion of the involute curve.

Line OE is further extended to meet the circle of radius $R_{2}$ at point $B$. Another line BG is drawn at an angle of $\beta_{2}$ to line OB. Where, the remaining part of the vane is formed by a smooth curve or another circular arc with centre G.

For an arc of a circle, the radius can be determined by;

$$
\rho_{2}=\frac{R 2^{2}-R 1^{2}}{2\left(R_{2} \operatorname{Cos} \beta_{2}-R_{1} \operatorname{Cos} \beta_{1}\right)}
$$

Where; radius $R_{1}$ is equal to OF and, angle $\beta_{1}$ is angle EFO. If thickness of the blade is kept constant, the drawn profile is the centre line for the vane.

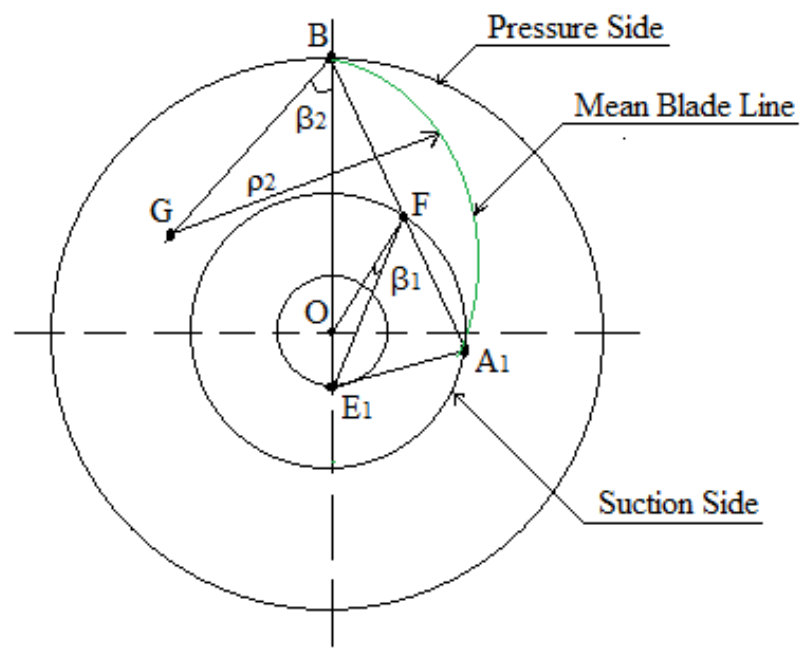

Fig-3: Double Arc method

\section{METHODS TO CALCULATE VOLUTE CASING}

\subsection{Principle of Constant Moment of Momentum}

This principle states that the moment of momentum remains constant at different sections, which can be expressed as;

$$
\mathrm{M}=\mathrm{C}_{\mathrm{u}} \mathrm{r}=\mathrm{C}_{\mathrm{u}_{1}} \mathrm{r}=\text { constant }
$$

\subsection{Principle of Constant Mean Velocity}

The discharge at any section of the volute can be obtained by;

$$
Q_{\emptyset}=\frac{\mathrm{Q} * \emptyset^{\circ}}{360^{\circ}}
$$

And, Area of volute at any section can be obtained by;

$$
A_{\varnothing}=\frac{\mathrm{Q}_{\varnothing}}{\mathrm{C}_{3}}=\frac{\mathrm{Q} \times \emptyset^{\circ}}{360^{\circ} \times \mathrm{C}_{3}}
$$

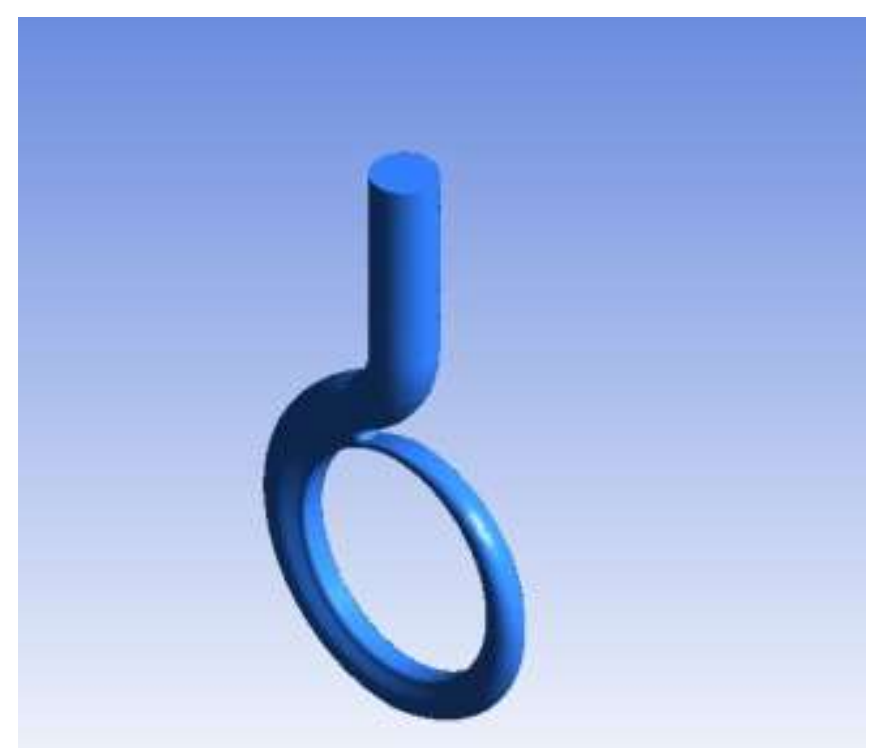

Fig-4: Model of Casing 


\section{MESHING OF PUMP ASSEMBLY}

The final mesh of the pump assembly was constructed using ANSYS. The corresponding model is shown in Fig.5. Meshing data with total number of elements and nodes are given in Table-3.

Table-3: Mesh information of pump assembly

\begin{tabular}{|c|c|c|c|c|}
\hline $\begin{array}{c}\text { Total } \\
\text { elements }\end{array}$ & $\begin{array}{c}\text { Total } \\
\text { nodes }\end{array}$ & TRI_3 & TETRA_4 & LINE_2 \\
\hline 5850460 & 1170192 & 235802 & 5610460 & 8150 \\
\hline
\end{tabular}

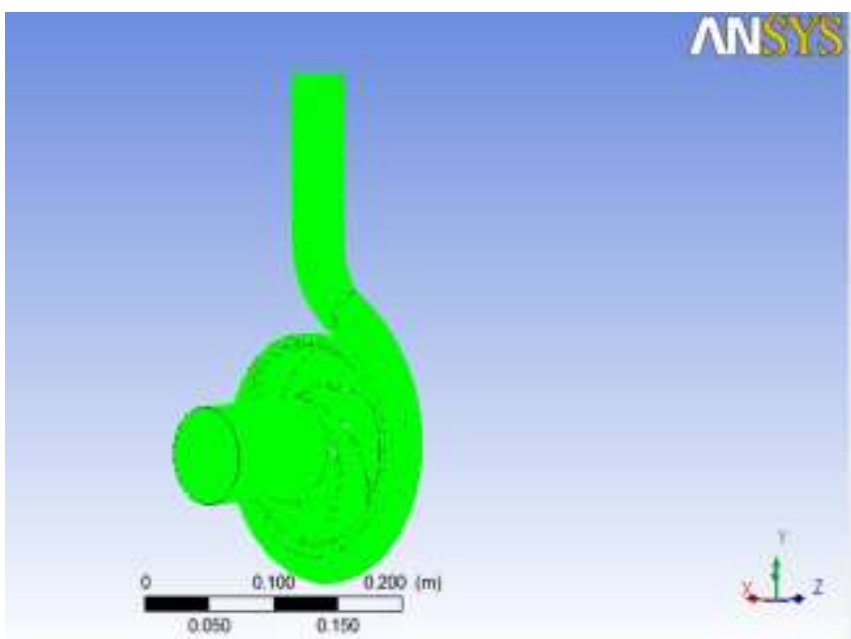

Fig-5: Meshing of designed pump.

\section{BOUNDARY CONDITIONS}

The numerical computation is based on steady-state condition with the following boundary conditions. Radial flow pump impeller domain is considered to be a rotating frame of reference with rotational speed of $2870 \mathrm{rpm}, 1 \mathrm{~atm}$. pressure at the inlet, and $0.0074 \mathrm{~m}^{3} / \mathrm{s}$ discharge at the outlet. The working fluid is water at $25^{\circ} \mathrm{C}$. $\mathrm{k}-\varepsilon$ turbulence model with turbulence intensity of $5 \%$ is used.

\subsection{Velocity Stream Contour}

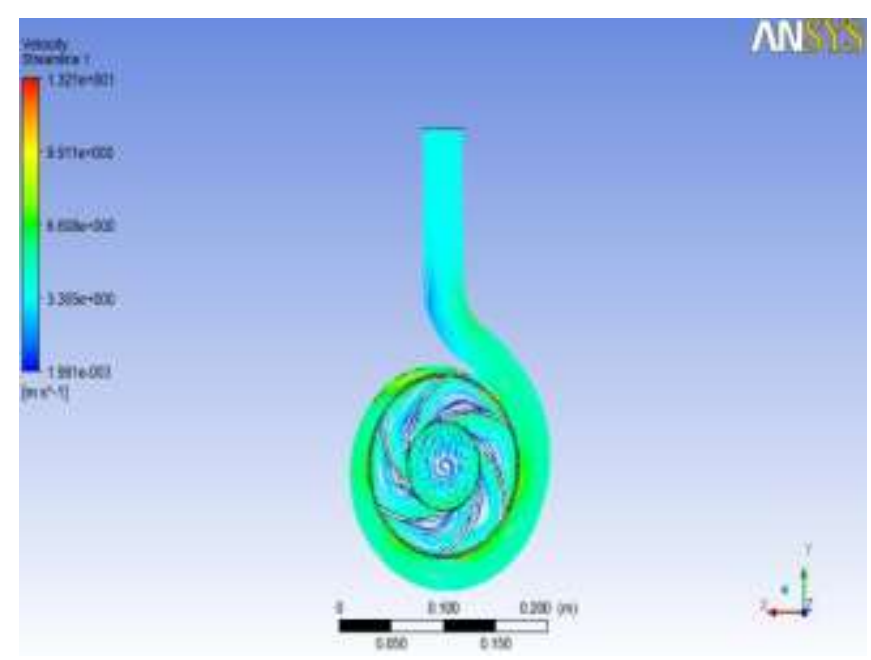

Fig-6: Velocity Stream Contour

\subsection{Pressure Contour}

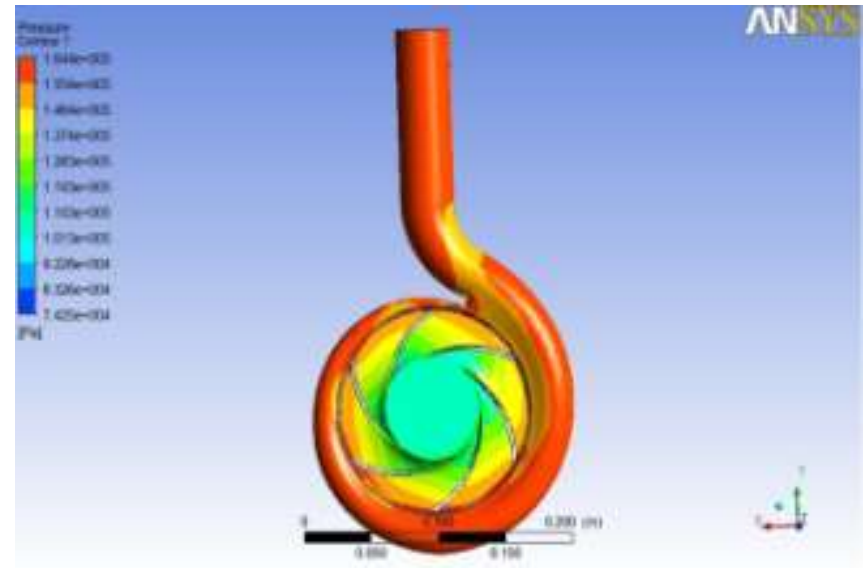

Fig-7: Pressure Contour

\section{RESULTS}

Inlet power (IP) can be calculated as;

$$
\begin{gathered}
\Rightarrow 2 \pi \mathrm{NT} / 60 * 1000 \\
\Rightarrow(2 \pi * 2870 * 19.63) / 60 * 1000 \\
\Rightarrow 5.899 \mathrm{KW}
\end{gathered}
$$

And, Outlet power (OP) can be calculated as;

$$
\Rightarrow(\mathrm{P} 0-\mathrm{Pi})^{*} \mathrm{Q} / 1000
$$$$
\Rightarrow(680522.42-18900.8) * 0.0074 / 1000
$$

$$
\Rightarrow 4.895 \mathrm{KW}
$$

So, Overall efficiency $=($ Outlet power $/$ Input power $)$

$$
\begin{gathered}
\Rightarrow 4.895 / 5.899 \\
\Rightarrow 0.8298
\end{gathered}
$$

\section{OPTIMIZATION OF RESULTS}

\subsection{Optimization of Number of Blades}

Table-4: Variation from number of blades

\begin{tabular}{|c|c|c|}
\hline Impeller & Number of blades & Efficiency (\%) \\
\hline Impeller 1 & 4 & 81.78 \\
\hline Impeller 2 & 5 & 82.49 \\
\hline Impeller 3 & 6 & 82.98 \\
\hline Impeller 4 & 7 & 83.78 \\
\hline Impeller 5 & 8 & 84.87 \\
\hline
\end{tabular}

\subsection{Results from Optimization}

Table-5: Impeller efficiency

\begin{tabular}{|c|c|c|c|}
\hline Impeller & $\begin{array}{c}\text { Inlet power } \\
(\mathbf{K W})\end{array}$ & $\begin{array}{c}\text { Outlet power } \\
(\mathbf{K W})\end{array}$ & Efficiency (\%) \\
\hline Impeller 1 & 5.078 & 4.153 & 81.78 \\
\hline Impeller 2 & 5.659 & 4.668 & 82.49 \\
\hline Impeller 3 & 5.899 & 4.895 & 82.98 \\
\hline Impeller 4 & 5.980 & 5.010 & 83.78 \\
\hline Impeller 5 & 6.003 & 5.095 & 84.87 \\
\hline
\end{tabular}




\subsection{Efficiency Vs Mass Flow Rate}

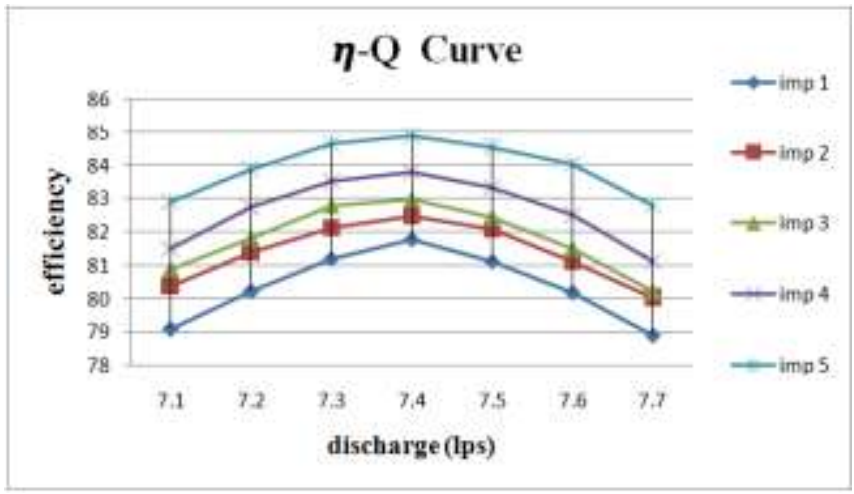

Fig-8: Efficiency Vs Mass Flow Rate

\section{CONCLUSION}

Based on the design and CFD analysis of radial flow impeller, it can be concluded that the performance of radial flow pump can be simulated by increasing the number of blades. The Optimum efficiency was obtained for Impeller 5 with eight (8) blades. It has been observed that the overall efficiency of pump at optimum value increases by $2.23 \%$.

\section{REFERENCES}

[1]. Gahlot, V. K., \& Nyiri, A. (1993). "Impeller Pumps, Theory and Design”, M.A.C.T, Bhopal, Madhya Pradesh, India.

[2]. Jain, S. V., Swarnkar, A., Motwani, K. H., \& Patel, R. N. (2015). "Effects of impeller diameter and rotational speed on performance of pump running in turbine mode", Energy Conversion and Management, 89, pp. 808-824.

[3]. Oyelami, A.T., Adejuyigbe, S.B., Waheed, M.A., Ogunkoya, A.K., \& Iliya, D. (2012). "Analysis of RadialFlow Impellers of Different Configurations", The Pacific Journal of Science and Technology, 13(1), pp. 24-33.

[4]. Anagnostopoulos, J. S. (2006). "CFD Analysis and Design Effects in a Radial Pump Impeller", WSEAS Transactions on Fluid Mechanics, 7(1), pp. 763-770.

[5]. Shah, S. R., Jain, S. V., Patel, R. N., \& Lakhera, V. J. (2013). "CFD for centrifugal pumps: a review of the state of the art", Procedia Engineering, 51, pp. $715-720$.

[6]. Jude, L., \& Homentcovschi, D. (1998). "Numerical analysis of the inviscid incompressible Flow in two dimensional radial-Flow pump impellers", Engineering Analysis with Boundary Elements, 22, pp. 271-279.

[7]. Egusquiza, E., Valero, C., Presas, A., Huang, X. X., Guardo, A., \& Seidel, U. (2016). "Analysis of the dynamic response of pump-turbine impellers. Influence of the rotor", Mechanical Systems and Signal Processing, 68-69, pp. 330341 .

[8]. Karanth, K. V., \& Sharma, N. Y. (2009). "CFD Analysis on the Effect of Radial Gap on Impeller-Diffuser Flow Interaction as well as on the Flow Characteristics of a Centrifugal Fan", International Journal of Rotating Machinery, 2009, pp. 1-8.

[9]. Pandit, H. C., Gundale, V.A., \& Patankar, R. C. (2016). "The Effect of Trimming the Diameter of a Radial type
Submersible Pump Impeller", Imperial Journal of Interdisciplinary Research, 2(5), pp. 1344-1349.

[10]. Somashekar, D., \& Purushothama, H. R. (2012), "Numerical Simulation of Cavitation Inception on Radial Flow Pump", IOSR Journal of Mechanical and Civil Engineering, 1(5), pp. 21-26.

[11]. Ramasamy, H., \& Prakash, P. (2015). "CFD Approach in the Design of Radial Flow Centrifugal Pump Impeller", International Journal of Scientific Engineering and Applied Science, 1(5), pp. 500-503.

[12]. Ajith, M. S., \& Issac, J. M. (2015). "Design and Analysis of Centrifugal Pump Impeller using ANSYS Fluent", International Journal of Science, Engineering and Technology Research, 4(10), pp. 3640-3643.

[13]. Ismail, M. A., Othman, Al. K., \& Zen, H. (2015). “An Experience with Simulation Modeling for Radial Flow Pump", International Journal of Emerging Engineering Research and Technology, 3(11), pp. 23-28.

[14]. Kaewnai, S., Chamaoot, M., \& Wongwises, S. (2009). "Predicting performance of radial flow type impeller of centrifugal pump using CFD", Journal of Mechanical Science and Technology, 23, pp. 1620-1627.

[15]. Chen, Z., Gu, Y., \& Fan, T. (2016), "Effect of sealing ring clearance on pump performance", WORLD PUMPS, March 2016, pp. 38-41.

\section{BIOGRAPHIES}

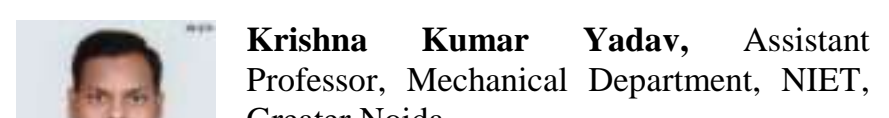
Greater Noida

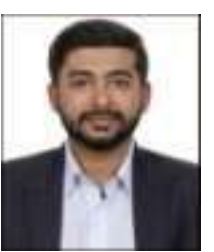

Karun Mendiratta, Assistant Professor, Mechanical Department, NIET, Greater Noida

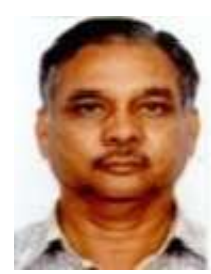

V. K. Gahlot, Professor, Civil Department, MANIT, Bhopal 